\title{
Mast cell chymase promotes angiogenesis and lymphangiogenesis mediated by activation of melanoma inhibitory activity gene family members in oral squamous cell carcinoma
}

\author{
MIYAKO KURIHARA-SHIMOMURA ${ }^{1,2^{*}}$, TOMONORI SASAHIRA ${ }^{1 *}$, \\ HIROYUKI SHIMOMURA ${ }^{2}$, ANJA KATRIN BOSSERHOFF ${ }^{3}$ and TADAAKI KIRITA ${ }^{2}$ \\ Departments of ${ }^{1}$ Molecular Pathology and ${ }^{2}$ Oral and Maxillofacial Surgery, \\ Nara Medical University, Kashihara, Nara 634-8521, Japan; ${ }^{3}$ Institute for Biochemistry, \\ Friedrich-Alexander University Erlangen-Nürnberg, D-91054 Erlangen, Germany
}

Received November 6, 2019; Accepted January 9, 2020

DOI: $10.3892 /$ ijo.2020.4996

\begin{abstract}
Mast cells (MCs) are present in the tumor stroma, and MCs that express the mast cell-specific proteases tryptase and chymase (MCTC) exhibit several tumor-related functions. It was previously reported that melanoma inhibitory activity (MIA) gene family members, including MIA, MIA2, and transport and Golgi organization protein 1 (TANGO), possess oncogenic functions in oral squamous cell carcinoma (OSCC). However, the relationships between $\mathrm{MC}_{\mathrm{TC}}$, and clinicopathological characteristics and activation of the $M I A$ gene family in OSCC remain unknown. In the present study, the functional roles of $\mathrm{MC}_{\mathrm{TC}}$ in patients with OSCC were investigated using immunohistochemistry and reverse transcription-quantitative PCR. In addition, the effects of extracellular chymase on oral cancer cells were examined. In patients with OSCC, $\mathrm{MC}_{\mathrm{TC}}$ density was significantly affected by tumor progression and nodal metastasis, and was correlated with vessel density. $\mathrm{MC}_{\mathrm{TC}}$ density was also correlated with $M I A$ and MIA2 expression. In OSCC cells, extracellular chymase promoted the secretion of vascular endothelial growth factor family proteins, and the transmigration and adhesion of HSC 3 cells to endothelial cells; knockdown of MIA, MIA2 and TANGO attenuated these effects. The present findings indicated that $\mathrm{MC}_{\mathrm{TC}}$ act as tumor-progressive factors in OSCC via the activation and secretion of MIA and MIA2, and the induction of angiogenesis and lymphangiogenesis.
\end{abstract}

Correspondence to: Dr Tomonori Sasahira, Department of Molecular Pathology, Nara Medical University, 840 Shijo-cho, Kashihara, Nara 634-8521, Japan

E-mail: sasa@naramed-u.ac.jp

${ }^{*}$ Contributed equally

Key words: mast cell, chymase, MIA gene family, oral cancer

\section{Introduction}

Oral squamous cell carcinoma (OSCC) is a common form of cancer, with an estimated 447,751 new cases and 228,389 deaths reported worldwide in 2018, which represents $\sim 2.5$ and $\sim 2.4 \%$ of all cancer incidence and mortality, respectively (1). In the USA, 53,000 new cases and 10,860 deaths from OSCC are estimated for 2019 (2). OSCC also exhibits high frequency in various other countries, including India, Sri Lanka, Pakistan, Afghanistan and Papua New Guinea; indeed, OSCC is the leading cause of cancer-related death among males in India and Sri Lanka (1). The incidence of OSCC, and lip and pharyngeal cancers is expected to increase in the future, reaching 855,900 new cases per year in 2035 due to changes in demographics (3). The overall 5-year survival rates of OSCC have not changed in the past 30 years, and remain $<50 \%$ (4). Therefore, early detection and treatment, and the clarification of the molecular details of OSCC remain essential to address this increasing health problem.

Considerable attention has been paid to the role of mast cells (MCs) in the tumor microenvironment (TME) (5). Human MCs are a rich source of the serine proteases tryptase and chymase; MCs that only contain tryptase are classified as $\mathrm{MC}_{\mathrm{T}}$, whereas those that contain both tryptase and chymase are classified as $\mathrm{MC}_{\mathrm{TC}}(5,6)$. Chymase acts indirectly to evoke angiogenesis through the activation of vascular endothelial growth factor (VEGF)-A, via the conversion of angiotensin I (Ang I) to Ang II and cleavage of matrix metalloproteinase-9 (MMP-9) (5). An increase in $\mathrm{MC}_{\mathrm{T}}$ count is closely associated with angiogenesis, cellular proliferation and poor prognosis in various types of cancer $(5,6)$. $\mathrm{MC}_{\mathrm{T}}$ also promote lymphangiogenesis by releasing VEGF-C and VEGF-D $(7,8)$, as well as overall immunosuppression $(5,9)$. However, previous studies focusing on the relationship between $\mathrm{MC}_{\mathrm{TC}}$ and tumors have been inconclusive. The accumulation of $\mathrm{MC}_{\mathrm{TC}}$ appears to be significantly associated with angiogenesis, nodal metastasis and/or poor prognosis in lung cancer (10-13), and $\mathrm{T}$ grade, clinical stage, angiogenesis and poor prognosis in gastric cancer (14). In contrast, low $\mathrm{MC}_{\mathrm{TC}}$ density is closely related to poor prognosis in melanoma (15) and colon cancer (16), and a 
more favorable immunophenotype in breast carcinoma (17). A strong negative correlation has also observed between melanoma proliferation and $\mathrm{MC}$ infiltration $(6,18)$. Therefore, the detailed roles of $\mathrm{MC}_{\mathrm{TC}}$ and chymase in various malignancies remain controversial.

Members of the melanoma inhibitory activity (MIA) gene family include MIA, MIA2, transport and Golgi organization protein 1 (TANGO or MIA3), and otoraplin. These secreted proteins share $34-45 \%$ amino acid and $47-59 \%$ cDNA sequence homology, and also possess a highly conserved Src homology 3-like domain $(4,19)$. Our previous studies reported that MIA gene family members act as oncogenes in OSCC by acting on the TME (4,20-24). One of the major functions of MIA and MIA2 in OSCC is the induction of angiogenesis and lymphangiogenesis through the activation of VEGF-A, VEGF-C and VEGF-D, as well as the general suppression of tumor immunity $(4,20-22,24)$. TANGO is also associated with microvessel density (MVD) and lymph vessel density (LVD) through the activation of platelet-derived growth factor $\beta$ polypeptide (PDGFB) $(4,23)$. $\mathrm{MC}_{\mathrm{TC}}$ in the TME may enhance the vasculogenic and immunosuppressive activity of the MIA gene family in OSCC. Thus, in the present study, the roles of $\mathrm{MC}_{\mathrm{TC}}$ and MIA gene family activation in OSCC were investigated.

\section{Materials and methods}

Tumor samples. Tissues were fixed over $96 \mathrm{~h}$ with formalin at $4^{\circ} \mathrm{C}$. Formalin-fixed, paraffin-embedded (FFPE) specimens of 93 primary OSCC (43 males and 50 females; age range, 45-89 years; mean, 66.8 10.7 years) without preoperative therapy were used in the present study. All specimens were selected at random from the Nara Medical University Hospital. Written informed consent was obtained from all individuals for the use of their tissue specimens. Tumor staging and the histological grade of OSCC were based on the Union for International Cancer Control (UICC) TNM classification system (8th edition) (25) and the World Health Organization criteria (26), respectively. Medical records and prognostic follow-up data were obtained from the patient database managed by the hospital. The present study was conducted following a protocol approved by the Medical Ethical Committee of the Nara Medical University (approval no. 719). The study protocol using human samples was performed according to the ethical standards stated in the Declaration of Helsinki.

Immunohistochemistry. Consecutive 3- $\mu \mathrm{m}$ sections were cut from each block, and immunohistochemistry was performed. An immunoperoxidase technique was performed following antigen retrieval with microwave treatment $\left(95^{\circ} \mathrm{C}\right)$ in citrate buffer ( $\mathrm{pH}$ 6.0) for $45 \mathrm{~min}$. Sections were pretreated with $3 \% \mathrm{H}_{2} \mathrm{O}_{2}$-methanol to block endogenous peroxidase activity at room temperature, and specimens were incubated in 10\% skim milk solution (Morinaga Milk Industry Co., Ltd.) for $20 \mathrm{~min}$ at room temperature to avoid false-positive antibody reactions. Antibodies (all diluted to $0.5 \mu \mathrm{g} / \mathrm{ml}$ ) specific for MC chymase (cat. no. ab2377; Abcam), CD34 (cat. no. M7165; Dako; Agilent Technologies, Inc.), used as a marker of endothelial cells, and the lymphatic vessel endothelial hyaluronan receptor 1 (LYVE1) antibody (cat. no. ab10278; Abcam), a marker for lymphatic endothelial cells, were used. After incubation at room temperature for $2 \mathrm{~h}$, sections were incubated with polyclonal anti-goat/mouse/rabbit Multi-Link secondary antibody (1:200; cat. no. E0453; Dako; Agilent Technologies, Inc.) for $30 \mathrm{~min}$ at room temperature. Specimens were visualized by exposure to diaminobenzidine solution (Dako; Agilent Technologies, Inc.), and counterstained with Meyer's hematoxylin (Sigma-Aldrich; Merck $\mathrm{KGaA}$ ) at room temperature for $10 \mathrm{~min}$.

Evaluation of immunohistochemistry. Verification of histological diagnoses and grading of immunohistochemistry were performed by two pathologists. To quantify the $\mathrm{MC}_{\mathrm{TC}}$ density, MVD and LVD, five strongly immunoreactive areas surrounding tumor cells were selected and examined using a light microscope (magnification, x200; BX53; Olympus Corporation), and densities were averaged. To determine the association between $\mathrm{MC}_{\mathrm{TC}}$ density and disease-free survival, the specimens were divided into two groups according to the $\mathrm{MC}_{\mathrm{TC}}$ density based on the overall mean value (23).

Laser capture microdissection (LCM). Laser capture microdissection was performed to specifically select OSCC cells for the preparation of small RNAs. Tissue sections $(7 \mu \mathrm{m})$ were prepared from each paraffin block, and stained using hematoxylin and eosin at room temperature for $10 \mathrm{~min}$. A PixCell II LCM microscope (Arcturus) was used to capture and transfer cells for microdissection according to the manufacturer's instructions; 5,000 tumor cells were acquired from each tissue sample.

Reverse transcription-quantitative polymerase chain reaction (RT-qPCR). Total RNA of tissues and cultured cells was extracted using an RNeasy FFPE Kit (Qiagen, Inc.), and $1 \mathrm{ng}$ of total RNA was converted to cDNA using a ReverTra Ace qRT kit (Toyobo Life Science) at $37^{\circ} \mathrm{C}$ for $15 \mathrm{~min}$ and $95^{\circ} \mathrm{C}$ for $5 \mathrm{~min}$. qPCR was performed on a StepOnePlus Real-Time PCR System (Applied Biosystems; Thermo Fisher Scientific, Inc.) with TaqMan Fast Universal PCR Master Mix (Applied Biosystems; Thermo Fisher Scientific, Inc.). The reactions were pre-incubated at $95^{\circ} \mathrm{C}$ for $20 \mathrm{sec}$, followed by 40 cycles of denaturation at $95^{\circ} \mathrm{C}$ for $1 \mathrm{sec}$ and annealing/extension at $60^{\circ} \mathrm{C}$ for $20 \mathrm{sec}$. Results were analyzed using the $2^{-\Delta \Delta \mathrm{Cq}}$ method (27). GAPDH mRNA was used as the internal control. The TaqMan Gene Expression Assays for MIA (cat. no. Hs00197954_m1), MIA2 (cat. no. Hs00365015_m1), TANGO/MIA3 (cat. no. Hs00412706_m1), and GAPDH (cat. no. Hs03929097_g1) were purchased from Applied Biosystems (Thermo Fisher Scientific, Inc.). All PCR reactions were performed in triplicate.

Cell culture and reagents. Our previous studies reported that OSCC-derived HSC3 cells overexpress MIA $(21,22)$, MIA2 (20) and TANGO (23). Therefore, HSC3 cells were used in the present study and maintained in Dulbecco's modified Eagle's medium (Wako Pure Chemical Industries, Ltd.) supplemented with $10 \%$ fetal bovine serum (Nichirei Biosciences, Inc.) and $10,000 \mathrm{U} / \mathrm{ml}$ penicillin/10,000 $\mu \mathrm{g} / \mathrm{ml}$ streptomycin (Wako Pure Chemical Industries, Ltd.) under $5 \% \mathrm{CO}_{2}$ and $95 \%$ air at 
$37^{\circ} \mathrm{C}$. Cells were treated with various concentrations $(0,5$ or $10 \mathrm{nM}$ ) of recombinant human chymase (R\&D Systems, Inc.) for $48 \mathrm{~h}$ at $37^{\circ} \mathrm{C}$.

Primary human umbilical vein endothelial cells (HUVECs) and primary human dermal lymphatic microvascular endothelial cells (HDLMVECs) were purchased from Cell Applications, Inc. HUVECs were cultured in endothelial cell media (Cell Applications, Inc.), and HDLMVECs were cultured in microvascular endothelial cell media (Cell Applications, Inc.), both with $5 \% \mathrm{CO}_{2}$ at $37^{\circ} \mathrm{C}$.

Small interfering RNA (siRNA). Stealth Select RNAi siRNAs for MIA (cat. no. HSS144615), MIA2 (cat. no. HSS133246) and TANGO (cat. no. HSS180081) were purchased from Thermo Fisher Scientific, Inc. AllStars Negative Control siRNA was used as a control (cat. no. SI03650318; Qiagen, Inc.). Cells were seeded (6,000 cells/well) in 24-well culture plates and cultured for $24 \mathrm{~h}$. Cells were transfected with $10 \mathrm{nM}$ siRNA using Lipofectamine ${ }^{\circledR} 2000$ (Invitrogen; Thermo Fisher Scientific, Inc.) according to the manufacturer's protocols. Subsequent experiments were performed after $48 \mathrm{~h}$ of transfection.

Immunoblotting. Whole cell lysates were obtained using M-PER $^{\text {TM }}$ Mammalian Protein Extraction Reagent (Thermo Fisher Scientific, Inc.). Protein concentrations of the lysates were determined by using a $\mathrm{DC}^{\mathrm{TM}}$ protein assay (Bio-Rad Laboratories, Inc.). Lysates (50 $\mu \mathrm{g} / \mathrm{lane})$ were subjected to $12.5 \%$ SDS-PAGE and immunoblotting by electrotransfer to PVDF membranes (Thermo Fisher Scientific, Inc.). Bullet Blocking One for Western Blotting (Nacalai Tesque, Inc.) was used as a blocking reagent (ready to use) at room temperature for $10 \mathrm{~min}$. The membranes were incubated with anti-MIA (1:10,000; cat. no. sc-377375; Santa Cruz Biotechnology, Inc.), anti-MIA2 (1:10,000; cat. no. ab58973; Abcam) and anti-TANGO/MIA3 antibodies (1:15,000; cat. no. LS-B4210; LifeSpan BioSciences, Inc.) for $12 \mathrm{~h}$ at room temperature. Binding of the primary antibodies was detected with peroxidase-conjugated anti-mouse (cat. no. sc-516102; Santa Cruz Biotechnology, Inc.) or anti-rabbit antibody $(1: 5,000$; cat. no. sc-2357; Santa Cruz Biotechnology, Inc.) for $2 \mathrm{~h}$ at room temerature. The immune complex was visualized with an ECL Western Blotting Detection System (Amersham; GE Healthcare Life Sciences). Anti-GAPDH antibody (1:10,000; cat. no. sc-20357; Santa Cruz Biotechnology, Inc.) was used as an internal control.

ELISA for MIA family. Cell culture medium was collected and centrifuged at $270 \mathrm{x} \mathrm{g}$ at $4^{\circ} \mathrm{C}$ for $10 \mathrm{~min}$. Proteins in the supernatant were then extracted using M-PER Mammalian Protein Extraction Reagent. ELISA kits were used to analyze MIA (cat. no. 11976826001; Roche Diagnostics), MIA2 (cat. no. LS-F16959; LifeSpan BioSciences, Inc.), TANGO/MIA3 (cat. no. LS-F52248; LifeSpan BioSciences, Inc.), VEGF-A (cat. no. RAB0508; Calbiochem; Merck KGaA), VEGF-C (cat. no. DVEC00; R\&D Systems, Inc.), VEGF-D (cat. no. DVED00; R\&D Systems, Inc.) and PDGFB (cat. no. DBB00; R\&D Systems, Inc.). The assays were performed according to the manufacturers' instructions and in triplicate. The presented data are the mean of three independent experiments.
Interaction assays of OSCCs and endothelial cells. The reciprocal actions of OSCC cells and endothelial cells were tested using a CytoSelect Tumor-Endothelium Adhesion Assay (Cell Biolabs, Inc.) in conjunction with the CytoSelect Tumor Transendothelial Migration Assay system (Cell Biolabs, Inc.) according to the manufacturer's protocols. Cellular adhesion and migration were measured using a Multiskan GO Microplate Spectrophotometer (Thermo Fisher Scientific, Inc.) at 480 and $520 \mathrm{~nm}$, respectively.

Statistical analysis. All statistical analyses were conducted using JMP13 (SAS Institute). Continuous data were presented as the mean $\pm \mathrm{SD}$. The differences in $\mathrm{MC}_{\mathrm{TC}}$ density between were analyzed by unpaired parametric t-test or one-way ANOVA, and multiple comparisons were analyzed by Tukey test. Moreover, cell experiments were analyzed using one-way ANOVA, and multiple comparisons were made using Tukey's test. The correlations between MVD, LVD and expression levels of $M I A$ gene family and $\mathrm{MC}_{\mathrm{TC}}$ density were analyzed with Pearson's correlation coefficient. Disease-free survival was calculated using the Kaplan-Meier method, and differences between groups were tested by means of a log-rank test. $\mathrm{P}<0.05$ was considered to indicate a statistically significant difference.

\section{Results}

$M C_{T C}$ density, MVD and LVD in OSCC specimens. First, $\mathrm{MC}_{\mathrm{TC}}$ density, MVD and LVD were evaluated in 93 patients with OSCC using immunohistochemistry. The mean \pm SD values of the $\mathrm{MC}_{\mathrm{TC}}$ density, MVD and LVD in OSCC cases were $49.7 \pm 30.6,50.6 \pm 34.5$ and $25.6 \pm 13.4$ cells or vessels/field of view, respectively (Fig. 1A-F). No expression of chymase was observed in OSCC cells.

The clinicopathological relevance of $\mathrm{MC}_{\mathrm{TC}}$ density in OSCC is presented in Table I. Significantly higher density was observed in patients with nodal metastasis compared with those without nodal metastasis $(\mathrm{P}=0.0029)$. Significant relationships were also found between the $\mathrm{MC}_{\mathrm{TC}}$ density and histological grade $(\mathrm{P}=0.0443)$, local progression ( $\mathrm{T}$ grade; $\mathrm{P}=0.0347)$, and clinical stage $(\mathrm{P}=0.0157)$. No relationship was found between $\mathrm{MC}_{\mathrm{TC}}$ density and other clinicopathological characteristics in OSCC. $\mathrm{MC}_{\mathrm{TC}}$ density was also correlated with MVD $(\mathrm{P}<0.0001)$ and LVD $(\mathrm{P}=0.0473)$ in OSCC (Fig. 1G and $\mathrm{H})$.

Relationship between $M C_{T C}$ density and MIA gene family expression in OSCC specimens. It was previously reported that the MIA gene family is associated with MVD and LVD in OSCC (20-24). Thus, the expression levels of MIA, MIA2 and TANGO were analyzed via RT-qPCR, and the correlations with $\mathrm{MC}_{\mathrm{TC}}$ density in OSCC specimens were evaluated. Expression levels of MIA $(\mathrm{P}=0.0023)$ and MIA2 $(\mathrm{P}=0.012)$ were correlated with $\mathrm{MC}_{\mathrm{TC}}$ density, whereas those of TANGO were not (Fig. 2A-C).

Relationship between $M C_{T C}$ density and OSCC prognosis. During the follow-up period, 17 of the 93 patients presented with a local or metastatic recurrence of cancer. The overall mean clinical follow-up time was 1,282 days, and ranged from 115 to 1,895 days. The disease-free survival curves suggested 
Table I. Relationships between chymase-positive MCTC density and clinicopathological characteristics.

\begin{tabular}{|c|c|c|c|}
\hline Parameters & $\begin{array}{l}\text { Number } \\
\text { of patients }\end{array}$ & $\begin{array}{l}\text { MCTC } \\
\text { density }\end{array}$ & P-value \\
\hline Age (years) & & & 0.6436 \\
\hline$\leq 60$ & $26(28.0 \%)$ & $52.1 \pm 36.9$ & \\
\hline$>60$ & $67(72.0 \%)$ & $48.8 \pm 28.1$ & \\
\hline Sex & & & 0.1136 \\
\hline Male & $43(46.2 \%)$ & $55.1 \pm 36.7$ & \\
\hline Female & $50(53.8 \%)$ & $45.0 \pm 23.7$ & \\
\hline Tumor site & & & 0.0869 \\
\hline Tongue & $52(55.9 \%)$ & $43.7 \pm 26.9$ & \\
\hline Gingiva & $27(55.9 \%)$ & $54.8 \pm 32.3$ & \\
\hline Other & $14(44.1 \%)$ & $61.9 \pm 34.4$ & \\
\hline Smoking habit & & & 0.7422 \\
\hline Yes & $45(48.4 \%)$ & $54.2 \pm 28.8$ & \\
\hline No & $48(51.6 \%)$ & $56.2 \pm 29.6$ & \\
\hline Alcohol intake & & & 0.4700 \\
\hline Habitual & $23(24.7 \%)$ & $53.2 \pm 28.6$ & \\
\hline Social & $53(57.0 \%)$ & $51.3 \pm 32.5$ & \\
\hline No drinking & $17(18.3 \%)$ & $42.3 \pm 19.6$ & \\
\hline Histological grade & & & 0.0443 \\
\hline Well & $62(66.7 \%)$ & $45.2 \pm 22.9$ & \\
\hline Moderate/Poor & $31(33.3 \%)$ & $58.7 \pm 41.0$ & \\
\hline $\mathrm{T}$ grade & & & 0.0347 \\
\hline $\mathrm{T} 1$ & $20(21.5 \%)$ & $40.2 \pm 32.0$ & \\
\hline $\mathrm{T} 2$ & $51(54.8 \%)$ & $47.8 \pm 27.6$ & \\
\hline T3-4 & $22(23.7 \%)$ & $64.0 \pm 35.2$ & \\
\hline Clinical stage & & & 0.0157 \\
\hline I & $20(21.5 \%)$ & $40.2 \pm 32.0$ & \\
\hline II & $38(40.9 \%)$ & $44.3 \pm 23.0$ & \\
\hline III-IV & $35(37.6 \%)$ & $61.0 \pm 33.1$ & \\
\hline Nodal metastasis & & & 0.0029 \\
\hline Negative & $63(67.7 \%)$ & $43.3 \pm 26.1$ & \\
\hline Positive & $30(32.3 \%)$ & $63.2 \pm 35.2$ & \\
\hline
\end{tabular}

$\mathrm{T}$ classification and clinical staging were performed according to TNM classification. Histological grade represents histological differentiation of squamous cell carcinoma (well-differentiated, moderately differentiated or poorly differentiated). Comparison of the MCTC density between groups was performed using t-tests or ANOVA. $\mathrm{P}<0.05$ was considered to indicate a statistically significant difference. Data are presented as the mean \pm SD. MCTC, mast cells expressing tryptase and chymase.

that cases with high $\mathrm{MC}_{\mathrm{TC}}$ density tended to have a poorer prognosis than those with lower $\mathrm{MC}_{\mathrm{TC}}$ density; however, there was no significant difference ( $\mathrm{P}=0.0801$; Fig. 3).

Effect of chymase on secretion of MIA family proteins, and angiogenesis and lymphangiogenesis in OSCC cells. HSC3 cells overexpress members of the MIA family (20-23). As MIA, MIA2 and TANGO are secretory proteins (4), the
A
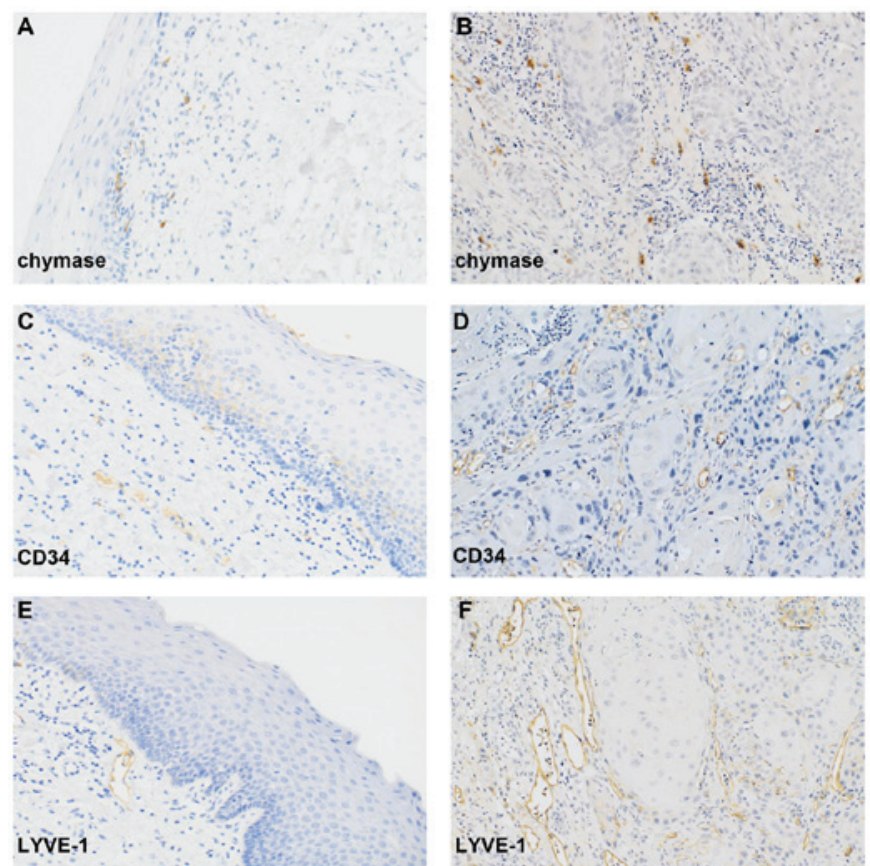

G
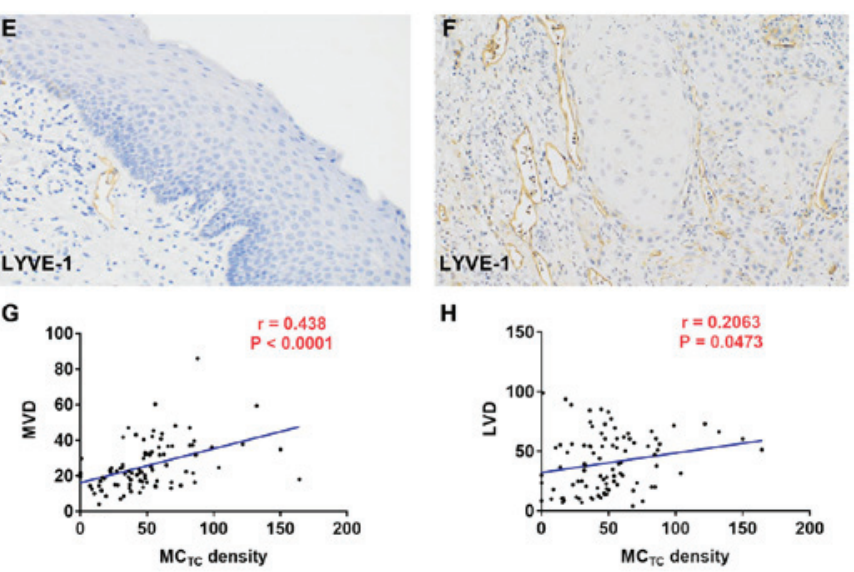

H

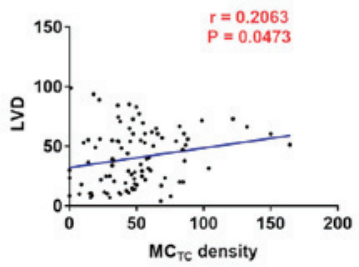

Figure 1. Expression of chymase, CD34 and LYVE1 in OSCC. (A and B) Chymase-positive mast cells, (C and D) CD34-positive blood vessels and (E and F) LYVE-1-positive lymph vessels in normal (A, C and E) mucosa and (B, D and F) OSCC. Magnification, x400. MCTC density was significantly correlated with (G) MVD and (H) LVD. OSCC, oral squamous cell carcinoma; LYVE1, lymphatic vessel endothelial hyaluronan receptor $1 ; \mathrm{MC}_{\mathrm{TC}}$, mast cells expressing tryptase and chymase; $\mathrm{MVD}$ microvessel density; LVD, lymph vessel density.

effect of chymase on the secretion and expression of the MIA gene family was evaluated in HSC3 cells. Secretion and expression of MIA and MIA2 was increased by treatment with recombinant human chymase, whereas MIA or MIA2 knockdown abolished the chymase-induced increase in MIA or MIA2 secretion (Fig. 4A-E). The secretion levels of TANGO were not affected by treatment with different concentrations of chymase in HSC-3 cells (Fig. 4D and E). These results suggested that chymase increases the expression and secretion of MIA and MIA2 in a paracrine manner in OSCC cells.

MIA and MIA2 are angiogenic and lymphangiogenic factors, inducing VEGF family activation, whereas TANGO promotes angiogenesis and lymphangiogenesis via the activation of PDGFB in HSC3 cells $(4,20-23)$. Next, the relationship between chymase and MIA gene family-induced angiogenesis and lymphangiogenesis was investigated. The secretion of VEGF-A, VEGF-C, and VEGF-D was increased following treatment with chymase in a dose-dependent manner in HSC3 cells, but not in MIA or MIA2 knockdown HSC3 cells (Fig. 5A-C). TANGO siRNA similarly attenuated chymase-induced increases in VEGF-A, VEGF-C and VEGF-D. Moreover, secretion levels of PDGFB were not 
A

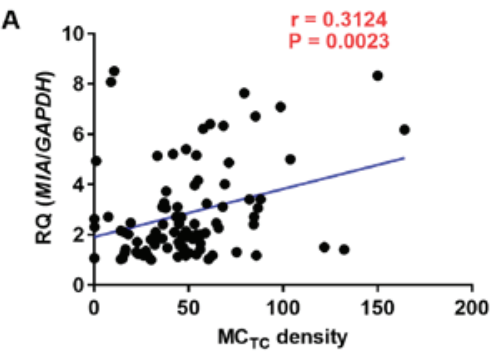

B

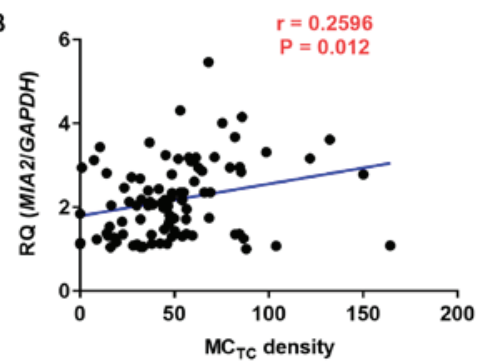

C

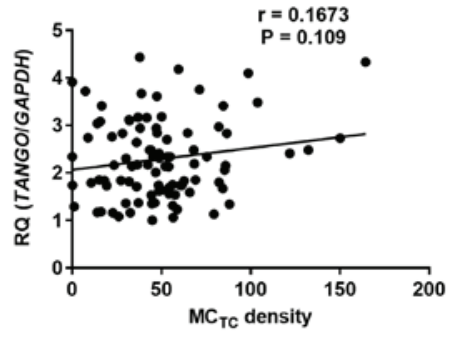

Figure 2. Relationship between $\mathrm{MC}_{\mathrm{TC}}$ density and $M I A$ gene family expression in the lysates of tumor tissues. $\mathrm{MC}_{\mathrm{TC}}$ density was correlated with (A) MIA ( $\mathrm{P}=0.0023)$ and $(\mathrm{B})$ MIA2 $(\mathrm{P}=0.012)$ expression levels. (C) TANGO expression levels were not correlated with $\mathrm{MC}_{\mathrm{TC}}$ density. $\mathrm{MC}_{\mathrm{TC}}$, mast cells expressing tryptase and chymase; MIA, melanoma inhibitory activity; TANGO, transport and Golgi organization protein 1; RQ, relative quantification.

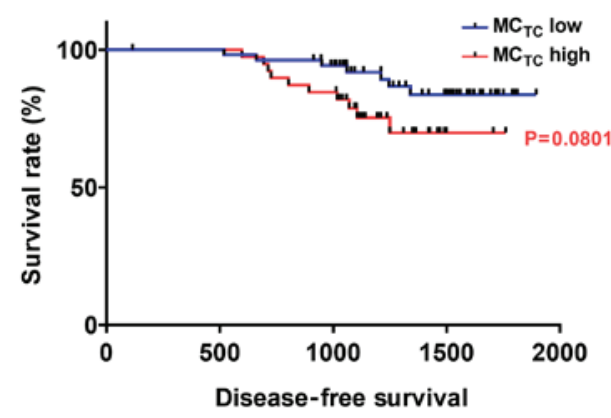

Figure 3. Disease-free survival analysis of patients with oral squamous cell carcinoma. Cases with high $\mathrm{MC}_{\mathrm{TC}}$ density exhibited a non-significant trend towards poorer prognosis compared with those with lower $\mathrm{MC}_{\mathrm{TC}}$ density. $\mathrm{MC}_{\mathrm{TC}}$, mast cells expressing tryptase and chymase.

affected by chymase treatment (Fig. 5D). Finally, although the adhesion and transmigration abilities of HSC3 cells to endothelial cells were increased by chymase treatment, these abilities were inhibited by MIA, MIA2 or TANGO siRNA (Fig. 5E-H).

Collectively, the present resulted suggested that chymase promotes OSCC progression by inducing MIAand MIA2-dependent angiogenic and lymphangiogenic mechanisms.
A
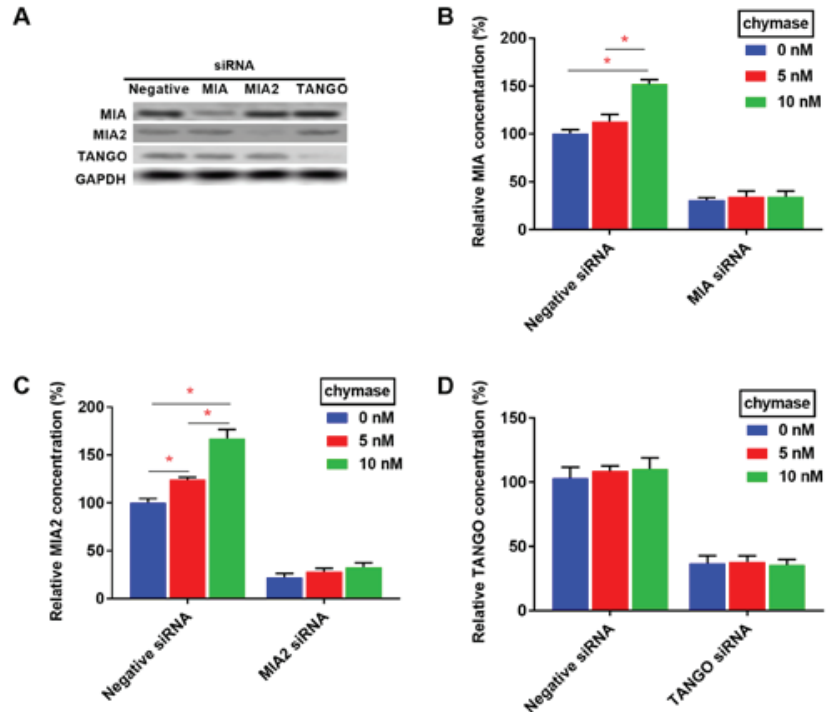

E

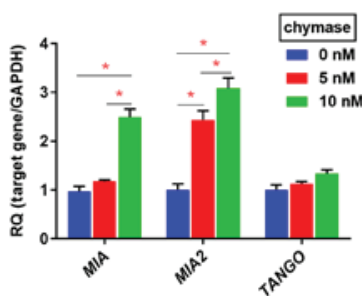

Figure 4. Effects of chymase on the secretion of the $M I A$ gene family and VEGF family. (A) Expression levels of MIA, MIA2, and TANGO in OSCC cells with or without knockdown treatment. Changes in (B) MIA, (C) MIA2, and (D) TANGO secretion and levels in OSCC cells treated with chymase and/or MIA gene family members treated with siRNA. (E) Changes in gene expression levels of $M I A$ gene family members by chymase treatment in OSCC cells. ${ }^{*} \mathrm{P}<0.05$. OSCC, oral squamous cell carcinoma; MIA, melanoma inhibitory activity; TANGO, transport and Golgi organization protein 1; siRNA, small interfering RNA; RQ, relative quantification.

\section{Discussion}

The TME is proposed to substantially contribute to cancer progression and metastasis (4). During this process, angiogenesis and lymphangiogenesis are pivotal events (21). Our previous study showed that high MVD and LVD, resulting from activation of the VEGF family, are strongly associated with $\mathrm{T}$ grade, clinical stage, nodal metastasis, local recurrence and poor prognosis in OSCC (21). MCs are present in the TME, and induce positive or negative effects on cancer (5,10-17). In human OSCC, an increase in $\mathrm{MC}_{\mathrm{T}}$ density is strongly associated with MVD (28). Mohtasham et al (29) also reported a gradual increase in $\mathrm{MC}_{\mathrm{T}}$ from oral dysplasia to OSCC. In addition, a separate study observed a significant increase in the numbers of $\mathrm{MC}_{\mathrm{TC}}$ in OSCC compared with healthy oral mucosa (30). Conversely, another study showed that the numbers of $\mathrm{MC}_{\mathrm{T}}$ decrease in OSCC and leukoplakia compared with normal oral mucosa (31). Hence, there remains substantial uncertainty regarding the role of MCs in OSCC, particularly the relevance of $\mathrm{MC}_{\mathrm{TC}}$ to lymphangiogenesis.

Chymase is a component of the renin-angiotensin system and plays a key role in blood pressure regulation $(32,33)$. In malignancies, chymase can cleave pro-MMP9 to produce MMP9, generate Ang II from Ang I, and induce angiogenesis via the activation of VEGF-A (5). Other studies have suggested 

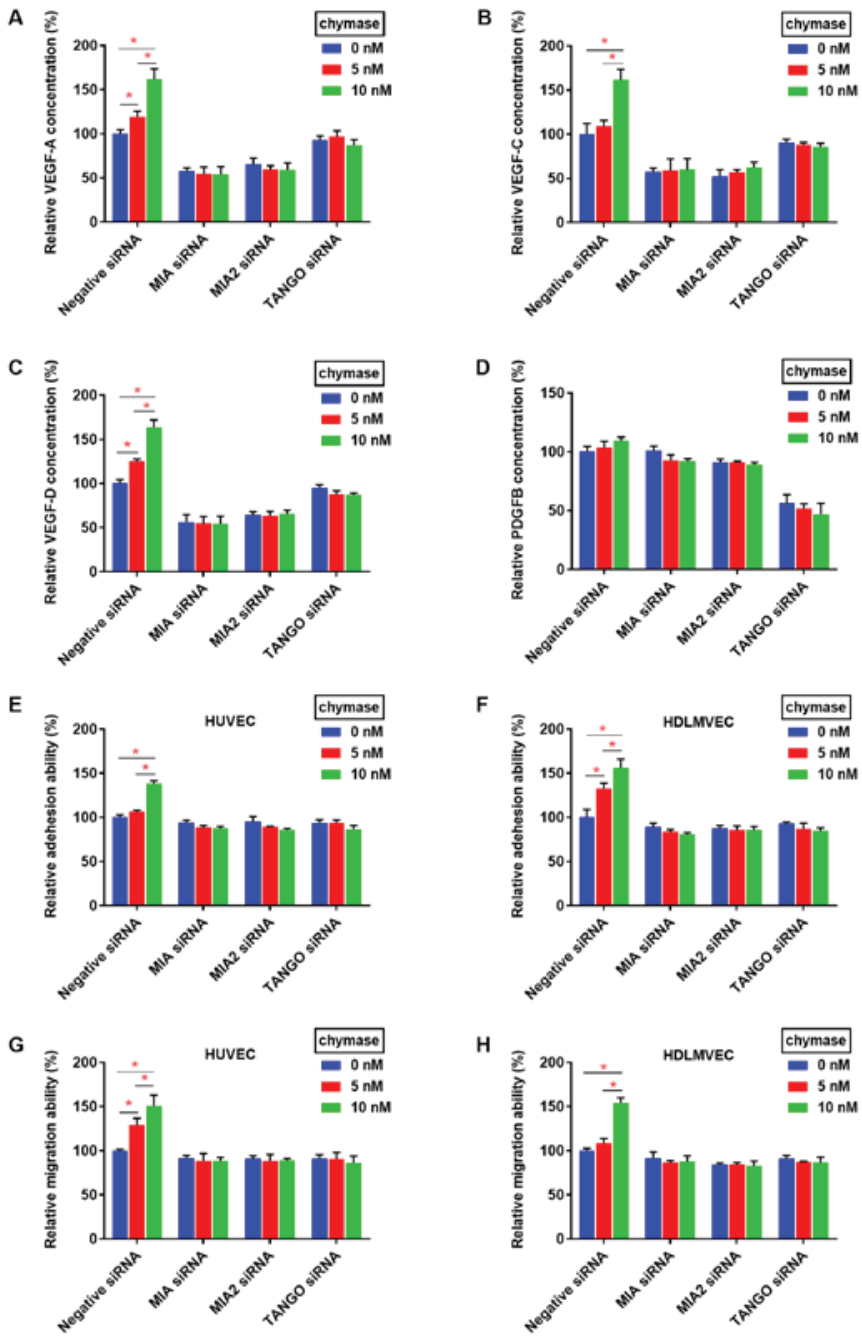

Figure 5. Effects of chymase on angiogenesis and lymphangiogenesis in OSCC cells. Effects of chymase and MIA gene family member siRNA transfection on (A) VEGF-A, (B) VEGF-C, (C) VEGF-C and (D) PDGFB secretion in OSCC cells. Changes in the $(\mathrm{E}$ and $\mathrm{F})$ adhesive and $(\mathrm{G}$ and $\mathrm{H})$ transmigratory abilities of HSC3 cells to endothelial cells following chymase treatment and/or MIA gene family member siRNA transfection. ${ }^{*} \mathrm{P}<0.05$. OSCC, oral squamous cell carcinoma; MIA, melanoma inhibitory activity; TANGO, transport and Golgi organization protein 1; PDGFB, platelet-derived growth factor $\beta$ polypeptide; siRNA, small interfering RNA; VEGF, vascular endothelial growth factor.

that $\mathrm{MC}_{\mathrm{T}}$ promote lymphangiogenesis by releasing VEGF-C and VEGF-D in mild and moderate periodontitis $(7,8,34)$. In the present study, it was revealed that $\mathrm{MC}_{\mathrm{TC}}$ density is associated with tumor progression and nodal metastasis in OSCC. Moreover, a significant correlation was observed between $\mathrm{MC}_{\mathrm{TC}}$ density, and MVD, LVD, and expression levels of MIA and MIA2 in OSCC specimens. In OSCC cells, chymase promoted angiogenesis and lymphangiogenesis through the secretion of VEGF-A, VEGF-C, and VEGF-D via MIA and MIA2 activation.

MIA/MIA2-integrin $\alpha 4 / \alpha 5$ signaling is regulated by the phosphorylation of mitogen-activated protein kinase p38 and c-Jun N-terminal kinase, and promotes OSCC progression, angiogenesis and lymphangiogenesis via upregulation of VEGF family activity $(4,20,21,24)$. As TANGO activates PDGFB-dependent neovasculogenesis in OSCC (23), it is proposed that chymase does not promote angiogenesis and

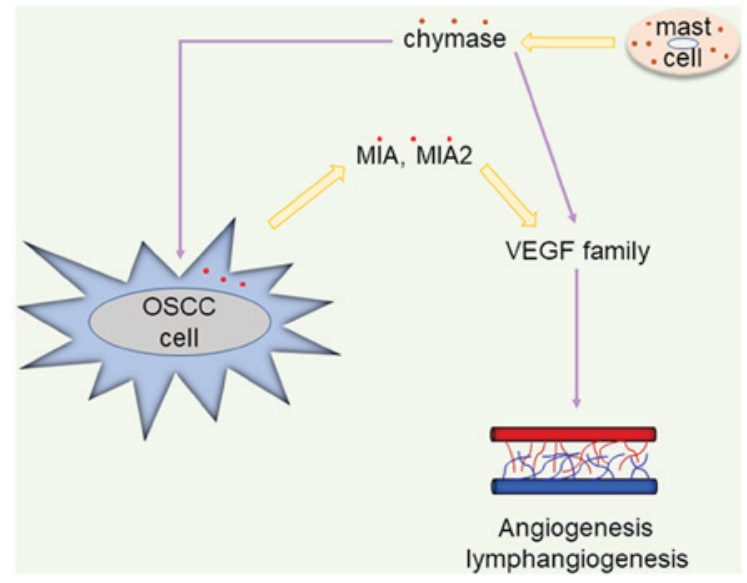

Figure 6. Schematic of the proposed actions of $\mathrm{MC}_{\mathrm{TC}}$ in OSCC. OSCC, oral squamous cell carcinoma; MIA, melanoma inhibitory activity; VEGF, vascular endothelial growth factor.

lymphangiogenesis via TANGO. The interaction of VEGF family members secreted by OSCC cells and $\mathrm{MC}_{\mathrm{TC}}$ may augment the potential for angiogenesis and lymphangiogenesis. A recent study suggested that chymase promotes cell detachment by decreasing E-cadherin, and facilitates the destruction of the extracellular matrix (ECM) through the activation of MMP-9 in human lung adenocarcinoma and squamous cell carcinoma cells (35). In cancer cells, MIA can bind to fibronectin, a major component of the ECM, and both MMP and MIA gene family receptors are cell surface integrins $(4,6,19,36)$. Chymase in the TME may enhance ECM destruction, angiogenesis and lymphangiogenesis by interacting with MIA secreted from cancer cells. Therefore, further studies are warranted to further understand the mechanisms underlying this process.

In general, the release of histamine, interleukin-10 and tumor necrosis factor- $\alpha$ from $\mathrm{MC}_{\mathrm{T}}$ leads to the suppression of tumor immunity in several malignancies (37). Cancer cells also suppress tumor immunity and create an environment in which they can easily grow $(20,37,38)$. Previous results have indicated that tumor-derived MIA may contribute to immune escape mechanisms frequently seen in patients with melanoma by suppressing the activation of immune cells and their associated antitumor cytotoxicity (38). Moreover, our previous study reported that MIA2 expression in OSCC is promoted by a disturbance in tumor immunity via the suppression of cytotoxic $\mathrm{T}$ lymphocytes and a relative increase in regulatory $\mathrm{T}$ lymphocytes (20). $\mathrm{MC}_{\mathrm{TC}}$ may also disrupt tumor immunity via interactions with MIA and MIA2 in OSCC cells. Additional studies are required to elucidate the immunosuppression observed following $\mathrm{MC}_{\mathrm{TC}}$ activation.

The functions and roles of chymase in tumor tissue remain controversial. Two polymorphisms in the chymase gene (CMA), CMA/A and CMA/B, are localized on chromosome 14 and associated with chymase expression (39). Sugimoto et al $(32,33)$ reported that the $C M A / B$ polymorphism in leukocytes is strongly associated with an increased risk of gastric cancer development and progression in Japanese populations. Conversely, Shimomoto et al (40) observed that the expression of MC chymase is upregulated in colon cancer-derived HT29 and CT26 cells, and the cytoplasm of colon cancer specimens. To our knowledge, there is no other 
report that chymase is expressed in epithelial cells. Therefore, there are questions regarding the findings of the aforementioned study, and further studies are required to determine the accurate expression of chymase in cancer cells.

Fig. 6 presents a proposed schematic of the mechanisms of $\mathrm{MC}_{\mathrm{TC}}$ in OSCC based on the findings of the present study. $\mathrm{MC}_{\mathrm{TC}}$ may accelerate angiogenesis and lymphangiogenesis via the activation of the VEGF family. Moreover, it is suggested that OSCC cells stimulated by chymase induce VEGF family secretion through MIA and MIA2, and promote angiogenesis and lymphangiogenesis in combination with $\mathrm{MC}_{\mathrm{TC}}$. Consequently, it is proposed that $\mathrm{MC}_{\mathrm{TC}}$ act as tumor promoting factors by upregulating MIA and MIA2 activity in OSCC. A previous study suggested that cimetidine inhibits the activation of MCs in patients with breast cancer (41). Additionally, c-kit signaling is critical for MCs and the antitumor effects of imatinib, a tyrosine kinase inhibitor with activity against c-kit, which are mediated via mast cell inhibition $(42,43)$. The antiangiogenic agents, sunitinib, sorafenib and nilotinib, have similar effects to imatinib, and may also be effective in suppressing cancer cells by regulating MC functions (37). Angiogenesis and lymphangiogenesis are pivotal events in tumor progression, and the resulting irregular neoplastic blood and lymphatic vessels interfere with the delivery of anticancer drugs (4). Normalization of the tumor vessels by using antiangiogenic and antilymphangiogenic treatments targeting the chymase-MIA gene family network may be useful methods for malignancies. However, the function of $\mathrm{MC}_{\mathrm{TC}}$ may vary depending on the type of cancer and clinical stage. More detailed studies are required to elucidate the varied roles of MCs; however, the present findings indicated the relevance of $\mathrm{MC}_{\mathrm{TC}}$ as a diagnostic and therapeutic target in OSCC.

\section{Acknowledgements}

Not applicable.

\section{Funding}

This work was supported by JSPS KAKENHI (grant nos. JP 17K11621 and 18K09796).

\section{Availability of data and materials}

The datasets used and/or analyzed during the current study are available from the corresponding author on reasonable request.

\section{Authors' contributions}

TS, AKB and TK conceived and designed the study. MKS, TS and HS acquired data. MKS, TS, HS and AKB analyzed and interpreted data. TS, MKS, AKB and TK drafted, revised and/or reviewed the manuscript. All authors read and approved the final manuscript.

\section{Ethics approval and consent to participate:}

The present study was approved by the Medical Ethical Committee of the Nara Medical University (approval no. 719). The study protocol using human samples was performed according to the ethical standards laid out in the Declaration of Helsinki.

\section{Patient consent for publication}

Not applicable.

\section{Competing interests}

The authors declare that they have no competing interests.

\section{References}

1. Bray F, Ferlay J, Soerjomataram I, Siegel RL, Torre LA and Jemal A: Global cancer statistics 2018: GLOBOCAN estimates of incidence and mortality worldwide for 36 cancers in 185 countries. CA Cancer J Clin 68: 394-424, 2018.

2. Siegel RL, Miller KD and Jemal A: Cancer statistics, 2019. CA Cancer J Clin 69: 7-34, 2019.

3. Shield KD, Ferlay J, Jemal A, Sankaranarayanan R, Chaturvedi AK, Bray F and Soerjomataram I: The global incidence of lip, oral cavity, and pharyngeal cancers by subsite in 2012. CA Cancer J Clin 67: 51-64, 2017.

4. Sasahira T and Kirita T: Hallmarks of cancer-related newly prognostic factors of oral squamous cell carcinoma. Int J Mol Sci 19: 19, 2018.

5. de Souza DA Jr, Santana AC, da Silva EZ, Oliver C and Jamur MC: The role of mast cell specific chymases and tryptases in tumor angiogenesis. BioMed Res Int 2015: 142359, 2015.

6. Bauer R, Humphries M, Fässler R, Winklmeier A, Craig SE and Bosserhoff AK: Regulation of integrin activity by MIA. J Biol Chem 281: 11669-11677, 2006.

7. Detoraki A, Staiano RI, Granata F, Giannattasio G, Prevete N, de Paulis A, Ribatti D, Genovese A, Triggiani M and Marone G: Vascular endothelial growth factors synthesized by human lung mast cells exert angiogenic effects. J Allergy Clin Immunol 123: 1142-1149, 1149.e1-5, 2009.

8. Sammarco G, Varricchi G, Ferraro V, Ammendola M, De Fazio M, Altomare DF, Luposella M, Maltese L, Currò G, Marone G, et al: Mast cells, angiogenesis and lymphangiogenesis in human gastric cancer. Int J Mol Sci 20: 20, 2019.

9. Jachetti E, Cancila V, Rigoni A, Bongiovanni L, Cappetti B, Belmonte B, Enriquez C, Casalini P, Ostano P, Frossi B, et al: Cross-talk between myeloid-derived suppressor cells and mast cells mediates tumor-specific immunosuppression in prostate cancer. Cancer Immunol Res 6: 552-565, 2018.

10. Nagata M, Shijubo N, Walls AF, Ichimiya $S$, Abe $S$ and Sato N: Chymase-positive mast cells in small sized adenocarcinoma of the lung. Virchows Arch 443: 565-573, 2003.

11. Ibaraki T, Muramatsu M, Takai S, Jin D, Maruyama H, Orino T, Katsumata T and Miyazaki M: The relationship of tryptase- and chymase-positive mast cells to angiogenesis in stage I non-small cell lung cancer. Eur J Cardiothorac Surg 28: 617-621, 2005.

12. Carlini MJ, Dalurzo MC, Lastiri JM, Smith DE, Vasallo BC, Puricelli LI and Lauría de Cidre LS: Mast cell phenotypes and microvessels in non-small cell lung cancer and its prognostic significance. Hum Pathol 41: 697-705, 2010.

13. Shikotra A, Ohri CM, Green RH, Waller DA and Bradding P: Mast cell phenotype, TNF $\alpha$ expression and degranulation status in non-small cell lung cancer. Sci Rep 6: 38352, 2016.

14. Kondo K, Muramatsu M, Okamoto Y, Jin D, Takai S, Tanigawa N and Miyazaki M: Expression of chymase-positive cells in gastric cancer and its correlation with the angiogenesis. J Surg Oncol 93: 36-42, discussion 42-43, 2006.

15. Siiskonen H, Poukka M, Bykachev A, Tyynelä-Korhonen K, Sironen R, Pasonen-Seppänen S and Harvima IT: Low numbers of tryptase+ and chymase+ mast cells associated with reduced survival and advanced tumor stage in melanoma. Melanoma Res 25: 479-485, 2015.

16. Mehdawi L, Osman J, Topi G and Sjölander A: High tumor mast cell density is associated with longer survival of colon cancer patients. Acta Oncol 55: 1434-1442, 2016.

17. Glajcar A, Szpor J, Pacek A, Tyrak KE, Chan F, Streb J, Hodorowicz-Zaniewska D and Okoń K: The relationship between breast cancer molecular subtypes and mast cell populations in tumor microenvironment. Virchows Arch 470: 505-515, 2017. 
18. Stieglitz D, Lamm S, Braig S, Feuerer L, Kuphal S, Dietrich P, Arndt S, Echtenacher B, Hellerbrand C, Karrer S, et al: BMP6-induced modulation of the tumor micro-milieu. Oncogene 38: 609-621, 2019.

19. Bosserhoff AK: Melanoma inhibitory activity (MIA): An important molecule in melanoma development and progression. Pigment Cell Res 18: 411-416, 2005.

20. Kurihara M, Kirita T, Sasahira T, Ohmori H, Matsushima S, Yamamoto K, Bosserhoff AK and Kuniyasu H: Protumoral roles of melanoma inhibitory activity 2 in oral squamous cell carcinoma. Br J Cancer 108: 1460-1469, 2013.

21. Sasahira T, Kirita T, Kurihara M, Yamamoto K, Bhawal UK, Bosserhoff AK and Kuniyasu H: MIA-dependent angiogenesis and lymphangiogenesis are closely associated with progression, nodal metastasis and poor prognosis in tongue squamous cell carcinoma. Eur J Cancer 46: 2285-2294, 2010.

22. Sasahira T, Kirita T, Oue N, Bhawal UK, Yamamoto K, Fujii K, Ohmori H, Luo Y, Yasui W, Bosserhoff AK, et al: High mobility group box-1-inducible melanoma inhibitory activity is associated with nodal metastasis and lymphangiogenesis in oral squamous cell carcinoma. Cancer Sci 99: 1806-1812, 2008.

23. Sasahira T, Kirita T, Yamamoto K, Ueda N, Kurihara M, Matsushima S, Bhawal UK, Bosserhoff AK and Kuniyasu H: Transport and Golgi organisation protein 1 is a novel tumour progressive factor in oral squamous cell carcinoma. Eur J Cancer 50: 2142-2151, 2014.

24. Sasahira T, Nishiguchi Y, Fujiwara R, Kurihara M, Kirita T, Bosserhoff AK and Kuniyasu H: Storkhead box 2 and melanoma inhibitory activity promote oral squamous cell carcinoma progression. Oncotarget 7: 26751-26764, 2016.

25. O'Sullivan B: Head and neck tumours. In: UICC TNM classification of malignant tumours. Brierley JD, Gospodarowicz MK and Wittekind C (eds). 8th edition. Wiley, Chichester, pp17-54, 2017.

26. Sloan P, Gale N, Hunter K, Lingen M, Nylander K, Reibel J, Salo $\mathrm{T}$ and Zain RB: Malignant surface epithelial tumors. In: WHO classification of head and neck tumors. El-Naggar AK, Chan JKC, Grandis JR, et al (eds). 4th edition. IARC Press, Lyon, pp17-54, 2017.

27. Livak KJ and Schmittgen TD: Analysis of relative gene expression data using real-time quantitative PCR and the 2(-Delta Delta C(T)) method. Methods 25: 402-408, 2001.

28. Iamaroon A, Pongsiriwet S, Jittidecharaks S, Pattanaporn K, Prapayasatok S and Wanachantararak S: Increase of mast cells and tumor angiogenesis in oral squamous cell carcinoma. J Oral Pathol Med 32: 195-199, 2003.

29. Mohtasham N, Babakoohi S, Salehinejad J, Montaser-Kouhsari L, Shakeri MT, Shojaee S, Sistani NS and Firooz A: Mast cell density and angiogenesis in oral dysplastic epithelium and lowand high-grade oral squamous cell carcinoma. Acta Odontol Scand 68: 300-304, 2010

30. Yadav A, Desai RS, Bhuta BA, Singh JS, Mehta R and Nehete AP: Altered immunohistochemical expression of mast cell tryptase and chymase in the pathogenesis of oral submucous fibrosis and malignant transformation of the overlying epithelium. PLoS One 9: e98719, 2014.
31. Oliveira-Neto HH, Leite AF, Costa NL, Alencar RC, Lara VS, Silva TA, Leles CR, Mendonça FE and Batista AC: Decrease in mast cells in oral squamous cell carcinoma: Possible failure in the migration of these cells. Oral Oncol 43: 484-490, 2007.

32. Sugimoto M, Furuta T, Kodaira C, Nishino M, Yamade M, Ikuma M, Sugimura $\mathrm{H}$ and Hishida A: Polymorphisms of matrix metalloproteinase-7 and chymase are associated with susceptibility to and progression of gastric cancer in Japan. J Gastroenterol 43: 751-761, 2008.

33. Sugimoto M, Furuta T, Shirai N, Ikuma M, Sugimura H and Hishida A: Influences of chymase and angiotensin I-converting enzyme gene polymorphisms on gastric cancer risks in Japan. Cancer Epidemiol Biomarkers Prev 15: 1929-1934, 2006.

34. Raica M, Cimpean AM, Popovici RA, Balica AR, Vladau M and Gaje PN: Mast cells stimulate lymphangiogenesis in the gingiva of patients with periodontal disease. In Vivo 29: 29-34, 2015.

35. Jiang Y, Wu Y, Hardie WJ and Zhou X: Mast cell chymase affects the proliferation and metastasis of lung carcinoma cells in vitro. Oncol Lett 14: 3193-3198, 2017.

36. Rolli M, Fransvea E, Pilch J, Saven A and Felding-Habermann B: Activated integrin alphavbeta 3 cooperates with metalloproteinase MMP-9 in regulating migration of metastatic breast cancer cells. Proc Natl Acad Sci USA 100: 9482-9487, 2003.

37. Dyduch G, Kaczmarczyk K and Okoń K: Mast cells and cancer: Enemies or allies? Pol J Pathol 63: 1-7, 2012.

38. Jachimczak P, Apfel R, Bosserhoff AK, Fabel K, Hau P, Tschertner I, Wise P, Schlingensiepen KH, Schuler-Thurner B and Bogdahn U: Inhibition of immunosuppressive effects of melanoma-inhibiting activity (MIA) by antisense techniques. Int J Cancer 113: 88-92, 2005.

39. Pfeufer A, Osterziel KJ, Urata H, Borck G, Schuster H, Wienker T, Dietz R and Luft FC: Angiotensin-converting enzyme and heart chymase gene polymorphisms in hypertrophic cardiomyopathy. Am J Cardiol 78: 362-364, 1996.

40. Shimomoto T, Ohmori H, Luo Y, Chihara Y, Denda A, Sasahira T, Tatsumoto N, Fujii K and Kuniyasu H: Diabetes-associated angiotensin activation enhances liver metastasis of colon cancer. Clin Exp Metastasis 29: 915-925, 2012.

41. Bowrey PF, King J, Magarey C, Schwartz P, Marr P, Bolton E and Morris DL: Histamine, mast cells and tumour cell proliferation in breast cancer: Does preoperative cimetidine administration have an effect? Br J Cancer 82: 167-170, 2000.

42. Yang FC, Ingram DA, Chen S, Zhu Y, Yuan J, Li X, Yang X, Knowles S, Horn W, Li Y, et al: Nf1-dependent tumors require a microenvironment containing $\mathrm{Nf}^{+/-}$- and c-kit-dependent bone marrow. Cell 135: 437-448, 2008.

43. Pittoni P,Piconese S, Tripodo C and Colombo MP: Tumor-intrinsic and -extrinsic roles of c-Kit: Mast cells as the primary off-target of tyrosine kinase inhibitors. Oncogene 30: 757-769, 2011. 